\title{
Assessing and managing the impact of duck hunting in Victoria - a new approach
}

RICHARD H. LOYN

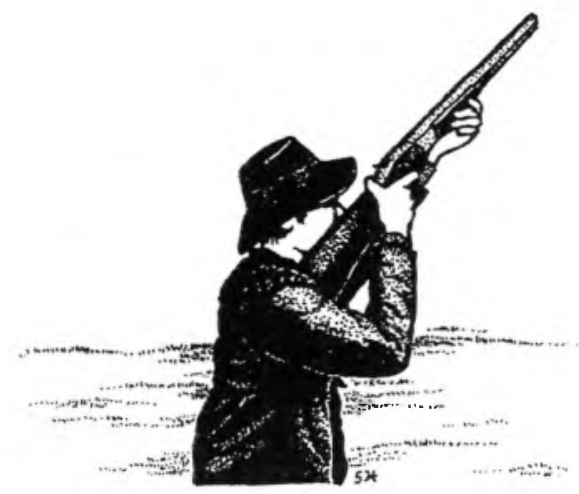

The impact of duck hunting in Victoria was assessed by comparing the take of game species and the kill of protected species with initial numbers of birds on large samples of wetlands. Numbers of birds were also measured on these wetlands after the opening weekend and at the end of the season. Estimates of annual production were made by examining samples of bagged ducks. This approach avoids the need to estimate total take or total population. Estimates of total population are expensive and impractical in many parts of the world.

The kill of protected species had little impact on numbers of any species except Freckled Duck Stictonetta naevosa. The take of game ducks exceeded annual production until 1990, when hunter numbers halved after introduction of a compulsory video test of their ability to identify water birds. Various other management options have been introduced or considered as part of a general review.

The issue (duck hunting)

Duck hunting is a popular and traditional activity in Victoria. It is opposed by animal welfare groups who focus on the killing of protected species. In 1986, the Victorian Department of Conservation and Environment commissioned a review of all aspects of duck hunting management (Loyn 1989), e.g. season, bag limits, lead shot, licensing and hunter education. It became clear that little was known of the impact of hunting on populations of game or protected species.

\section{The context (Victoria)}

Victoria is a state in southeastern Australia, a little smaller than New Zealand or the UK. Its rainfall is higher and more relisble than that over much of the Australian interior, and there is a relative abundance of wetlands that consistently contain water. Over 60,000 of its four million people have hunted ducks in recent years. Resident populations of ducks are often supplemented by influxes from ephemeral swamps in inland Australia, which are the main breeding area for several species (Frith 1982, Braithwaite et al. 1986). The ten week duck season in Victoria now runs from March to May (autumn), and eight native duck species can then be shot legally. They are Australian
Shelduck Tadorna tadornoides, Pacific Black Duck Anas superciliosa, Grey Teal A. gibberifrons, Chestnut Teal $A$. castanea, Australasian Shoveler A. rhynchotis, Pink-eared Duck Melacorhynchus membranaceus, Hardhead or White-eye Aythya australis and Maned Goose or Australian Wood Duck Chenonetta jubata.

\section{Key Questions}

Key questions in the review were identified as: (i) What proportion of each species is killed every year (annual \% kill); and (ii) what proportion of each species has been produced every year, in terms of young birds surviving to the start of the hunting season (annual production)? It was realised that both values could be estimated on samples of waters without knowing the size of the total population, or the place of origin of young or adult birds.

The first question can be answered by comparing the kill on selected wetlands, with initial numbers of birds on those wetlands. A large sample of wetlands must be examined so that influxes and effluxes of birds tend to balance out. An estimate must also be made of the proportions of birds initially on wetlands open and closed to hunting. The second question can be answered by determining the proportion of young birds in the population at the start of the 


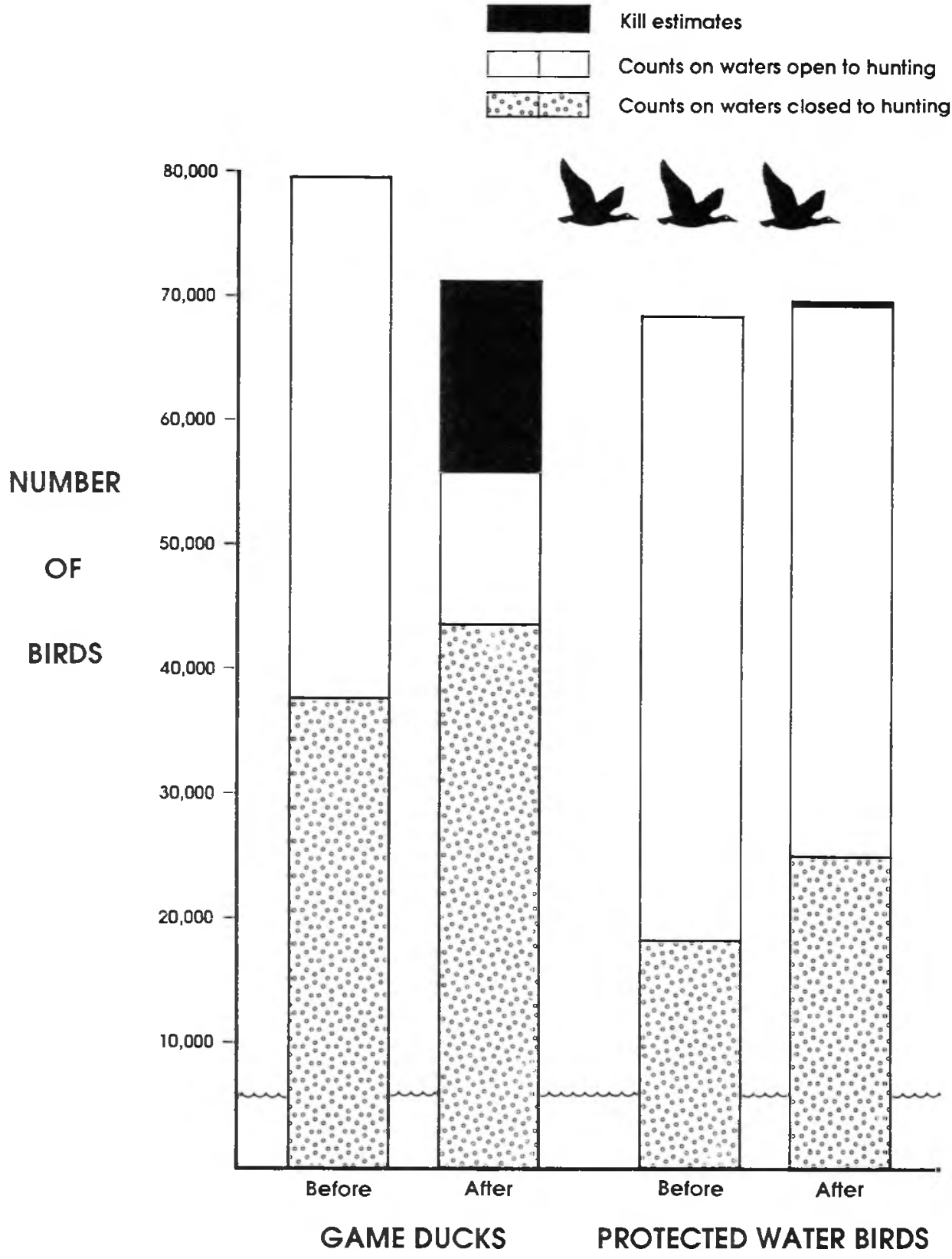

Figure 1. Counts of game and protected species on selected waters before and after opening weekend, 1987 to 1989 (mean of three annual totals), and independent estimates of kill on those same waters over opening weekend.

season. Opening day is the appropriate time to determine this, and it is also the time when a large sample of birds can be examined most easily - from hunters' bags. There is no need to make separate estimates of production and mortality of eggs and ducklings.
Both answers will be approximate, as some biases are involved. In particular, it is well known that young birds may be shot more readily than adults, inflating estimates of annual production. Some observers may underestimate the initial number of birds, especially on veg- 
etated wetlands, inflating estimates of annual \% kill. However, methods could be devised to measure these biases. It is considered that the biases are unlikely to be large enough to affect the value of results as first approximations.

This approach is a departure from the usual practice in the Northern Hemisphere of estimating the total number of birds taken by hunters (total take) and total populations for a country, region or flyway (Boyd 1983, Harradine 1985, Tamisier 1985). Estimates of total take for Victoria have already been published (Norman \& Powell 1981), but corresponding estimates of total population have proved impractical to obtain. Annual aerial transects have been run in eastern Australia since 1983 (Braithwaite et al. 1986), but they are designed to measure changes not absolute numbers, and the clumped distribution of waterfowl precludes extrapolation. Estimates of total population are expensive and impractical in many regions of the world.

\section{Methods}

Three key initiatives were taken early in the review:

1. A Summer Waterfowl Count (three weeks before duck season), was instigated as a tool for locating Freckled Duck Stictonetta naevosa and monitoring numbers of all species and their potential exposure to hunting. Freckled Duck belong to an endemic monospecific genus; they are rare and many are shot when they visit populated parts of Australia (Corrick 1982, Martindale 1986). The count is done by contract to the Royal Australasian Ornithologists Union (RAOU) and involves observers from the RAOU, Victorian Field and Game Association (VFGA) and the Department of Conservation and Environment (DCE) (Martindale 1988, Hewish 1988, Peter 1989, 1990). Water birds are now counted on over 600 wetlands, with a total count in 1990 of 385,000 game ducks and 225,000 protected water birds (grebes, coot, swans and three protected duck species) (Peter 1990).

2. A programme of water bird counts was started on selected wetlands before and after opening weekend and again at the end of the season. In 1990 these were made on 65 wetlands open to hunting and 55 wetlands closed to hunting. Surveys of hunters' bags (a traditional DCE activity, e.g. Norman \& Powell 1981) and hunter numbers are made on the same wetlands over opening weekend, along with counts of dead protected or game birds left along the shore. A sample of bagged ducks is examined to determine proportions of young birds. The \% kill over opening weekend is calculated by expressing the take on the sample of wetlands, as a percentage of initial numbers on the same sample of wetlands.

3. A mail survey is conducted by sending questionnaires to 500 hunters at the end of the season, with phone-calls to selected non-responders (Loyn \& Timms 1987 and unpublished reports). One of several objectives is to determine how many ducks were taken in the whole season compared with those taken at opening weekend (seasonal ratio).

Several other management initiatives were made, including a reduced bag limit of two Australasian Shoveler, a ban on night hunting, and introduction by 1990 of compulsory video tests in which hunters must demonstrate a certain standard in water bird identification before they are authorised to hunt ducks.

\section{Results}

In each of the first three years (1987 to 1989), numbers of game birds declined over opening weekend, by an amount greater than the estimated kill (Fig. 1). The decline on waters open to hunting was partly balanced by movement to waters closed to hunting. Over the first three years, the mean \% kill of game ducks was estimated as $34 \%$ of initial populations on waters open to hunting ( 31.4 to 37.2 ) or $22 \%$ of those on waters open and closed to hunting (21.8 to 23.8), using the Summer Waterfowl Count as the best measure of hunting exposure.

The mail survey showed that the mean seasonal ratio was 3.07 (2.84 to 3.33 ); although hunting is most intense at opening weekend, only a third of the season's take is made at that time. By multiplying these results, the annual \% kill was estimated as $66 \%$ of initial populations on waters open and closed to hunting (63.9 to 79.3). Post-season counts indicated net emigration of ducks during the season. In contrast, total numbers of protected birds showed little change over opening weekend (Fig. 1). Declines on waters open to hunting were virtually matched by increases on waters closed to hunting.

Nevertheless, many protected birds were found shot, and the mean observed kill was $0.40 \%$ of initital populations on waters open to hunting (where shoreline searches were made) or $0.29 \%$ of those on waters open and closed to hunting. Some birds would have been shot and 


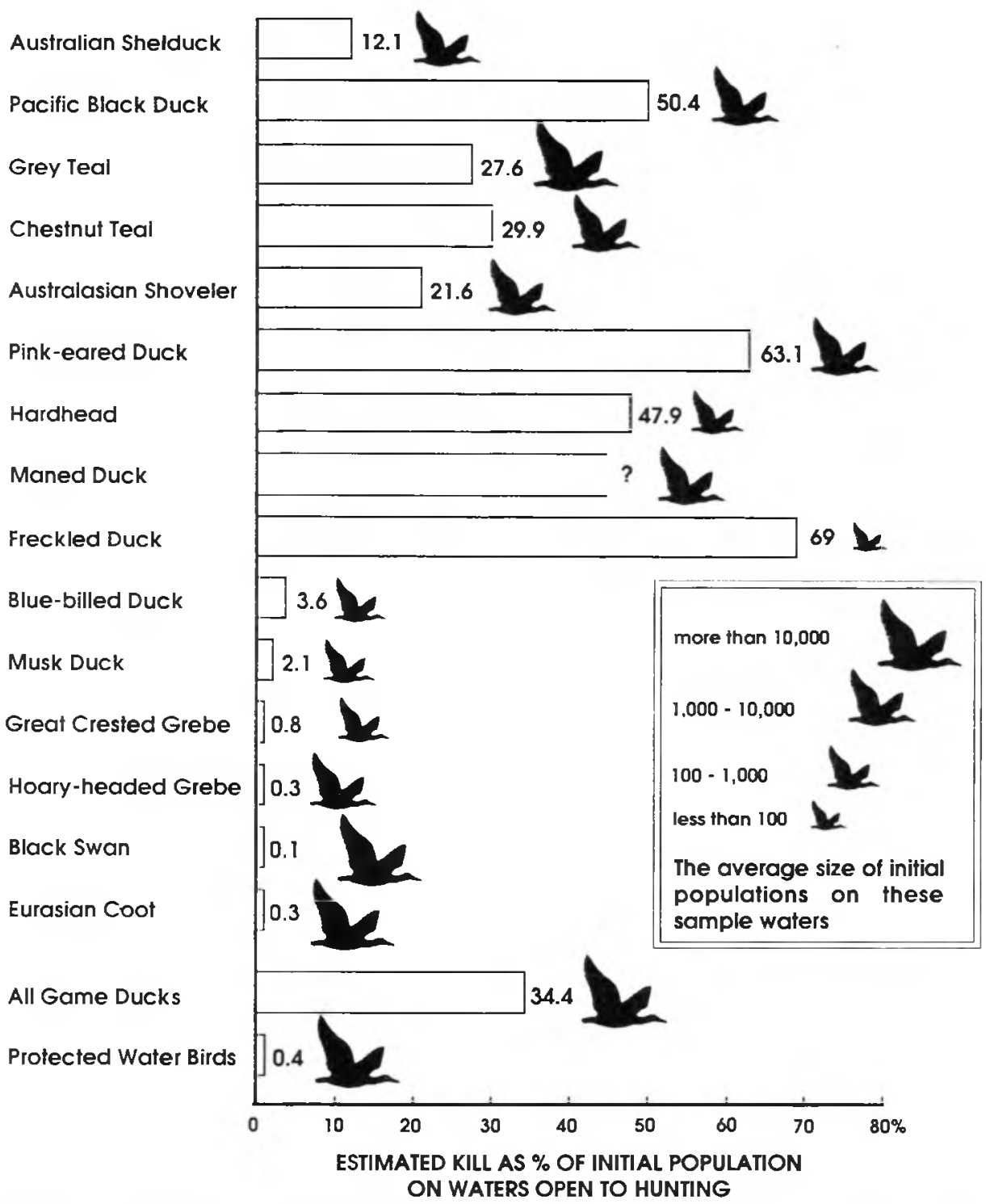

Figure 2. Vulnerability of each species over opening weekend: estimated kill as $\%$ of initial population on selected waters open to hunting, 1987 to 1989 (mean of three annual estimates).

not found, but not to the extent of reducing the measured population. Individual protected birds were almost a hundred times less likely to be shot and found than individual game ducks were to be taken, on wetlands where counts, shoreline surveys and bag surveys were made.

Some protected species were more likely than others to be shot over opening weekend (Fig. 2). Distinctive protected birds such as Black Swans were unlikely to be killed though a few still get caught in crossfire. The two protected stifftail ducks were more vulnerable,
Blue-billed Duck Oxyura australis more so than Musk Duck Biziura lobata (which rarely flies). Freckled Duck are an outstanding exception, and appear to be at least as likely to be shot as game species.

Among game species, Australian Shelduck has consistently been the least vulnerable, and Pink-eared Duck the most, on wetlands open to hunting. Shelduck depart quickly when shooting begins, often flying high and taking refuge on pasture or dry salt lakes. They are large (not easily brought down) and reputed to be tough to 


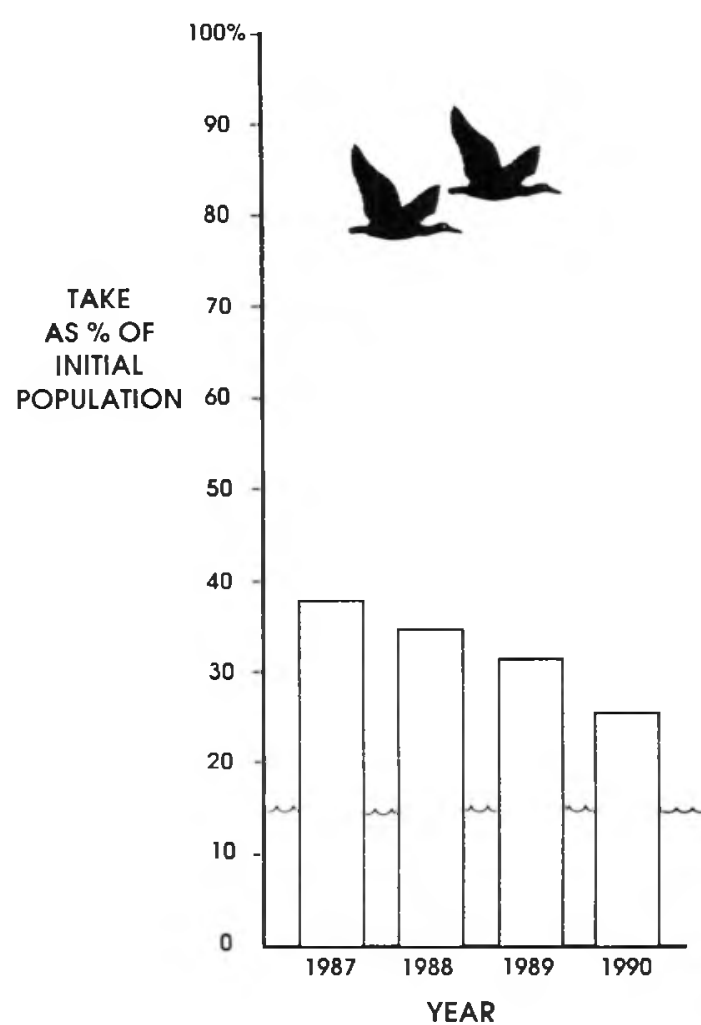

(a) Opening weekend, as $\%$ of population on waters open to hunting

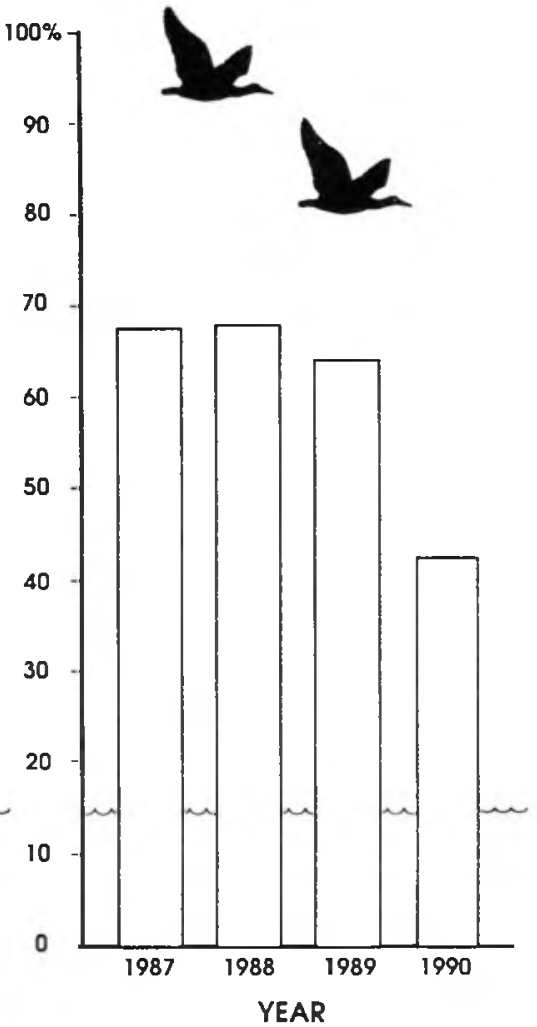

(b) Whole season as $\%$ of population on waters open and closed to hunting

Figure 3. Annual estimates of kill of game species (take) as $\%$ of initial population. In 1990 there were half as many hunters as before; bags were high and impact was low.

Figures for (b) are calculated as follows:

(annual \% kill) $=$ (opening weekend vulnerability) $\times$ (exposure) $\mathrm{x}$ (seasonal ratio)

where

1. (opening weekend = Kill over opening weekend on waters open to hunting, as \% of initial populations on those vulnerability) waters (Fig. 3a).

2. (exposure) = Estimated numbers on waters open to hunting at start of season, as \% of those on waters open and closed (from Summer Waterfowl Count).

3. (seasonal ratio) = Ratio of ducks taken in whole season, to those taken at opening weekend (from mail survey to sample of hunters).

eat (hence avoided by many hunters). In contrast, Pink-eared Duck are small and tame, and rarely escape by day to other waters (Maher 1982, Loyn 1987). Fortunately, Pink-eared Ducks are less exposed to hunting than other game species (low \% on wetlands open to hunting during Summer 'Waterfowl Count). An inverse correlation has been noted across species between vulnerability and exposure to hunting ( $\mathrm{r}=0.64, P=0.0017$, for game species other than Australian Wood Duckover the three years). It is not known whether this is due to sheer good fortune, or to genetic selection. Selection would act strongly against subpopulations of vulnerable species if they were genetically likely to visit groups of waters that happened to be open to hunting. It is clear that a species as vulnerable as Pink-eared Duck would quickly become extinct locally if it were as exposed to hunting as Australian Shelduck. This is exactly the situation that applies to Freckled Duck in Victoria, but in most years much of the population remains inland where it is presumably less exposed to hunting. 
Results obtained for Australian Wood Duck are unreliable as the species is common on small farm dams which were undersampled. Hunting on such dams is often restricted or prohibited by the owners, and hence our estimates of \% kill and exposure to hunting are too high for this species. Small farm dams do not form a major habitat for other game species.

The mean annual production of game ducks in the three years 1987-89 was estimated as 55\% of first year birds in the samples of bagged ducks at the start of each season (50.7 to 59.8). This is similar to the average value of $50 \%$, calculated by Loyn (1989) from data collected from 1972 to 1981 (e.g. Braithwaite \& Norman 1981, F.I. Norman pers comm.).

\section{The answers}

Although the comparisons are approximate, it appears that more game birds were being taken in those three years (mean $=66 \%$ of initial populations), than could be replenished by the populations sampled on those waters (mean \% first year $=55 \%$ ). Victoria's hunters may be drawing on populations from other regions of Australia, regularly making a population vacuum that may be filled to various degrees by birds that would not otherwise have immigrated to the state. This is similar to the situation in some European countries, described as "parasitism" by Tamisier (1985).

Results suggest that the focus of further management should be on regulating the take of game ducks, and on protecting Freckled Duck. This differs from the public perception that the general kill of protected species is the main problem.

\section{Actions (what to do)}

Regulating take of game ducks: After the 1987 results, the opening-day bag limit was reduced from 20 to ten. However, it was recognised that this would have little effect as few people obtain such high bags. Changes to season length were likely to be similarly insensitive. More direct changes could be made by controlling hunter numbers or improving the refuge system (reducing exposure). The last approach was favoured, and a statewide review of refuges is planned. A suggested goal was for $50 \%$ exposure of ducks to hunting at the start of the season, compared with $60-70 \%$ at present. Protecting Freckled Duck: From 1990, all hunters must identify Freckled Duck correctly on video, as well as a proportion of other species, to be authorised to hunt duck in Victoria. The education programme continues. The main emphasis will be on locating flocks of Freckled Duck (mainly through the Summer Waterfowl Count) and closing selected waters to hunting. Criteria have been developed for strategic temporary closures (Loyn 1989).

Protecting other Water Birds: The education programme has already reduced the kill of protected species. Hunters accept the need to keep improving standards.

\section{Outcomes (are these actions working?)}

In 1990, the seasonal take of game ducks was at its lowest level as \% of initial population (Fig. 3 ), and for the first year it fell below the mean level of annual production. Numbers of ducks remaining after opening weekend were conspicuously higher than in previous years. This result could be due to a combination of factors. The last three breeding seasons had been successful in various parts of the birds' ranges, and dry conditions further north in Australia in summer 1989-90 may have compelled more ducks than usual to visit Victoria. High numbers were recorded on the Summer Waterfowl Count (Peter 1990), but by the start of the season it was estimated that numbers were similar to the previous year, on waters counted at both times. Most importantly, the number of active hunters had halved to 24,000 in 1990 , as an unintended consequence of the video identification test. This has been evident in the field, and is not simply due to a switch to illegal hunting. Remaining hunters obtained high bags but had reduced impact on duck numbers.

The level of take is still higher than in North America (20\%, Boyd 1983) and similar to that in Europe (Tamisier 1985). It is not known if the present level of take is sustainable, but it seems that in 1990, hunting in Victoria would have had less impact on Australian duck populations than in previous years. The observed kill of protected birds was less in $1990(0.11 \%$ of initial populations on waters open and closed to hunting) than in previous years.

Freckled Duck were not numerous in 1990 (presumably remaining inland) and it is too early to assess any change in hunters' ability to avoid the species. Temporary closures of waters over the four years have reduced the species' exposure to hunting. 


\section{Conclusions}

The work has shown that useful information can be generated rapidly about the impact of hunting, without estimating absolute size of population or kill, by studying bird numbers and kill on large samples of waters. The main need is to compare take with initial numbers, but comparisons of counts before and after the opening weekend help complete this picture. Mail surveys are needed to extrapolate results to the whole season, and post-season counts to check for net immigration or emigration. In the event of net immigration, the estimated seasonal take (on the sample of waters) should be related to the estimated immigrant population on those waters. This approach could be applied in many parts of the world where estimates of absolute population size are impractical. It is recommended as a routine part of hunting management. The information has been used in selecting management strategies in Victoria and assessing their results. There is agreement that the management of duck hunting has been improved.

Many thanks to the large number of people who helped collect this information, from $D C E, R A O U$, $V F G A, B O C A$ and other organisations. I also thank George Mifsud for drafting the figures and Irene Prentice for typing the paper. The successful hunter education programme was run by the late Ron Brown, whose vision and energy culminated in the introduction and acceptance of the video identification test. He will be missed.

\section{References}

Boyd, H. 1983. Intensive regulation of duck hunting in North America: its purpose and achievements. Canadian Wildlife Services Occasional Paper 50, 24 pp.

Braithwaite, L.W., Maher, M., Briggs, S.V. \& Parker, B.S. 1986. An aerial survey of three game species of waterfowl (Family Anatidae) populations in eastern Australia. Aust. Wildl. Res. 13:213-23.

Braithwaite, L.W. \& Norman, F.I. 1981. The 1977 and 1978 open seasons on waterfowl in south-eastern Australia. C.S.I.R.O. Div. Wildl. Res. Tech. Mem. 15, 41 pp.

Corrick, A.H. 1982. Records of Freckled Duck in Victoria from December 1980 to July 1981 and of the number shot on opening day of the 1981 duck season. Aust. Bird Watcher 9:260-68.

Frith, H. J. 1982. Waterfowl in Australia. 3rd edition, Angus \& Robertson.

Harradine, J. 1985. Duck shooting in the United Kingdom. Wildfowl 36:81-94.

Hewish, M.J. 1988. Waterfowl count in Victoria, February 1988. RAOU Rep. 52, 69 pp.

Loyn, R.H. 1987. A report on the 1987 duck hunting season in Victoria. ARI Tech Rep. 61, 20 pp.

Loyn, R.H. 1989. The management of duck hunting in Victoria - a review. ARI Tech. Rep. 79, 85 pp.

Loyn, R.H. \& Timms, R. 1988. Hunter mail survey and counts of water birds after the 1987 duck hunting season in Victora. ARI Tech. Rep. 83, 20 pp.

Maher, M. 1982. Response by waterfowl to hunting pressure: a preliminary study. Aust. Wildl. Res. 9:527-31.

Martindale, J. 1986. The Freckled Duck - an RAOU Conservation Statement. RAOU Rep. 22, 12 pp.

Martindale, J. 1988. Waterfowl count in Victoria, January 1987. RAOU Rep. 37, 40 pp.

Norman, F.I. \& Powell, D.G. M. 1981. Rates of recovery of bands, harvest patterns and estimates for Black Duck, Chestnut Teal, Grey Teal and Mountain Duck shot during Victorian open seasons, 1953-77. Aust. Wildl. Res. 8:659-64.

Peter, J. 1989. Waterfowl count in Victoria, February 1989. RAOU Rep. 57, 56 pp.

Peter, J. 1990. Waterfowl count in Victoria, February 1990, RAOU Rep. 72, 45 pp.

Tamisier, A. 1985. Hunting as a key environmental parameter for the Western Palearctic duck populations. Wildfowl 36:95-103.

Richard H. Loyn, Department of Conservation and Environment, 123 Brown St., Heidelberg, Vic. 3084, Australia. 